\title{
Practices of poverty alleviation by open and distance education: a case report from the Open University of China
}

Practices of poverty alleviation by

ODE

\author{
Chuanjin Ju, Songyan Hou, Dandan Shao, Zhijun Zhang and \\ Zhangli $\mathrm{Yu}$ \\ The Open University of China, Beiing, China
}

\begin{abstract}
Purpose - The purpose of this report is to demonstrate open and distance education (ODE) can support poverty alleviation. Taking the practices of the Open University of China (the OUC) as an example, this paper aims to reveal how open universities make contributions to local residents in rural and remote areas.

Design/methodology/approach - Focusing on 25 poverty-stricken counties, the OUC had invested 58 million RMB to its learning centers in these counties from 2017 to 2020 . The first one is to improve ICT and educational facilities in these learning centers. The second approach is to cultivate local residents with degree programs through ODE so as to promote local economic development. The third one is to design and develop training programs according to local context to meet the specific needs of local villagers.

Findings - After 3 years working, cloud-based classrooms and computer rooms have been set up. Bookstores have been founded and printed books have been donated. Hundreds of thousands of digital micro lectures have been supplied to these learning centers which have been improved and fully played their functions. Nearly 50,000 local residents have been directly benefited. Village leaders have helped lift local residents out of poverty. Poverty-stricken villagers have been financed to study on either undergraduate or diploma programs. Local residents have improved their skills by learning with the training programs offered by the OUC.

Originality/value - ODE is proved to be an effective way to eradicate poverty. Open universities are proved to be able to make contributions to social justice. By fulfilling its commitments to eliminate poverty within the national strategy framework, the OUC has built its brand nationwide.
\end{abstract}

Keywords The Open University of China, Open and distance education, Poverty alleviation, Education equity Paper type Case study

\section{Background}

Chinese poverty alleviation has experienced three stages since the foundation of the People's Republic of China in 1949. i.e. the first stage was from 1949 to 1977 when socialism was established, which provided an institutional system for poverty elimination; the second stage was from the reform and opening up policy in 1978 onwards, a change from passive to active in the aspect of poverty alleviation policy; and the third one was from the 18th National Congress of the Communist Party of China (CPC) in 2012-2020, a period of transforming from large-scale poverty alleviation to targeted poverty alleviation, with an aim of eradicating absolute and extreme poverty in China (Bohui Zhao, 2019). Great achievements have been made over the past 70 years, which has paved a solid foundation for building a moderately prosperous society. Notably, since 2012, more than 10 million people have been lifted out of

(C) Chuanjin Ju, Songyan Hou, Dandan Shao, Zhijun Zhang and Zhangli Yu. Published in Asian Association of Open Universities Journal. Published by Emerald Publishing Limited. This article is published under the Creative Commons Attribution (CC BY 4.0) licence. Anyone may reproduce, distribute, translate and create derivative works of this article (for both commercial and non-commercial purposes), subject to full attribution to the original publication and authors. The full terms of this licence

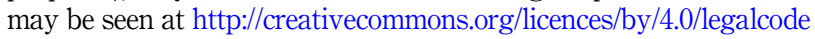

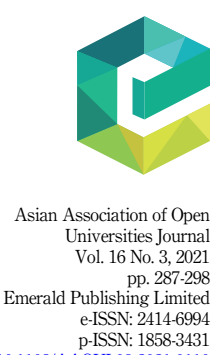

Received 14 September 202

Revised 26 October 2021

Accepted 28 October 2021 
AAOUJ 16,3

poverty annually; the number of this population is equal to that of a medium-sized country (Xi, 2021). In February 2021, Chinese President Xi Jinping announced China's eradication of extreme poverty to the world, the final 98.99 million impoverished rural residents living under the current poverty line were lifted out of poverty, all the 832 impoverished counties and 128,000 impoverished villages have been removed from the poverty list (Xi, 2021). Regional poverty has been eradicated, and the task of defeating extreme poverty has been fulfilled. With such achievements, China has created another "miracle" that will go down in history $(\mathrm{Xi}, 2021)$ !

However, this process and progress are not easy and full of difficulties and challenges, particularly in China, such a huge country. To eradicate poverty has encountered many obstacles even in the latest stage. One of them is how to lift local residents in rural and remote areas out of poverty.

Chinese famous sociologist Mr. Fei Xiaotong claims in his book Earthbound China: "From the perspective of grassroots, Chinese society is rural because population is not dynamic and life there is inclined very much to locality." (Fei, 2013, p. 5) This is typical in Chinese rural and remote areas. In 2007, China's population receiving higher education accounted for $6.56 \%$ of the total national population. In 2017, this figure increased to $13.88 \%$ (Li, 2019). However, compared with China's total population of 1.4 billion, the above data show that there is still a large amount of the population unable to receive higher education. Lower education background and fewer opportunities to participate in the competition are obstacles for rural people to find a job and settle in big cities. Therefore, population with poor education background stays or flows to villages and towns where higher education is not very much needed. No doubt, in these areas people are more likely to be trapped in Matthew effect because of the relatively limited online and offline education resources. Hence, the negative cycle of population quality needs to be addressed urgently and economic and social development in rural and remote areas needs to be improved.

How to eradicate poverty for the population discussed in the above is a great concern of Chinese government. It is clearly mentioned in the national strategy framework of poverty alleviation, education is an integral part of the overall course of poverty alleviation in China. It is believed that education is a fundamental way of cutting off the intergenerational transmission of poverty and plays a long-term role in helping poor people out of poverty (Institute of Party History and Literature of the CPC Central Committee, 2018). Educational institutions, teachers and students are the core targets to be lifted out of poverty in China. The purposes are to improve institutions' capacity in running education, to fully develop teachers' professional ability and to cultivate students' all-round development in povertystricken areas.

In 2015, the 13th five-year National Development Plan set a goal to fully eradicate poverty by the end of 2020 . Therefore, related organizations would make their contributions to this goal. As the main provider of open and distance education (ODE), the Open University of China (OUC) has the obligation to fulfill this commitment and started to implement this practice since 2017. Achievements have been made and it is necessary to provide an evaluation so that experience in this practice can be transmitted into the next stage, i.e. rural revitalization. This article reports the specific practices that the OUC has adopted in eliminating poverty by ODE. For eradicating poverty, the OUC has adopted several solutions which have been evaluated in this report. The practices have demonstrated that ODE is an effective way to improve local residents' education and skills, which can help them get rid of poverty.

\section{Why ODE is used to alleviate poverty}

Chinese society is featured with "rural China" and "online China". The former refers to poverty-stricken rural areas where economic development and public services have fallen 
behind; whereas the latter is urban areas where the economy is booming in all walks of life driven by modern information technology headed by the "Internet plus". The development in Chinese rural areas is lagged that of urban areas, and there is a big gap between the two areas. However, with the advancement of Chinese Internet infrastructure and the popularity of smart phones, residents in "rural China" can learn simple knowledge via the Internet. Chinese Minister Chen Baosheng said when evaluating the effect of COVID-19 pandemic on Chinese education: "COVID-19 provides an unprecedented experimental opportunity for massive online learning." (Jing, 2021, p. 9) This shows that an "online China" in all areas is approaching. Hence, to supporting "rural China" with the advantages of "online China" is a potential way, and the characteristics of Chinese society under the dual structure of urban and rural areas are the foundation of implementing ODE.

\section{Literature review}

ODE in China started in 1980s and related research began in 1990s, mainly focusing on policies, teachers' qualification and capacity, learner support, student's satisfaction, registration, examination, course design and development and ICT. Since the practice of poverty alleviation by ODE was implemented very late in China, research concentrated in this field is less. However, poverty alleviation using education is a key research area, ranging from subject to theories and from practice and mode. Yang and Lin (2017) claim that it is necessary for higher education institutions to be involved in poverty eradication, and such institutions have the responsibilities and obligations to solve poverty problems in rural and remote areas. $\mathrm{Li}$ (2017) states that improving educational conditions and widening educational access are the starting point of assuring education equity. Chen and Chen (2017) examine that there are several modes of poverty alleviation using education, one of which is to deliver education through ODE.

\section{Aims and questions}

The OUC aims to help people in "rural China" with learning resources in "online China" through ODE. But the question is, How?

\section{The case study}

To solve the questions, the OUC started to select target areas. The running system of the OUC is composed of 3 levels, with the headquarters in Beijing as the first level and the provincial OUs as the second level and the learning centers nationwide as the third one. Till 2017, there were nearly 4,000 learning centers nationwide. In order to implement targeted poverty alleviation, a dedicated research team was organized in the headquarters to identify what and how to support local residents to alleviate poverty through ODE. The team conducted research and investigation many times, particularly in those rural and remote areas. After investigation, the team identified 25 poverty-stricken counties (see Appendix) in 12 provinces and autonomous regions in central and western parts of China as the destination. Research presents a clearer picture of the natural condition and economic development in 25 povertystricken counties. Following this research, comparative studies between these 25 counties and China's top 100 counties were analyzed and compared, from which areas needed to be improved were identified. A report was drafted for reference. Then the team conducted field studies based on the report. They also identified the situation of ODE in the 25 learning centers there. And a decision was made to implement poverty alleviation through ODE in the learning centers.

Terrain condition is the most basic element in the natural conditions of an area. The literature review shows that most of the 25 counties are mountainous terrain, with complex topography, including mountains, plateaus, river valleys, hills, etc. with high altitude,
Practices of poverty alleviation by ODE

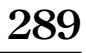


AAOUJ 16,3

fragmented and irregular plots, unsuitable for large-scale agricultural development. The cost of construction of transportation and other infrastructure is rather high and full of difficulties. GDP is a barometer of regional economic development. The per capita GDP of the 25 counties in 2017 was 20,364 yuan/person, which was about one-third of the total China's per capita GDP of 59,501 yuan/person in 2017 and less than one-fifth of the 2017 China's top 100 counties' per capita GDP of 106,000 yuan/person (China Daily, 2018). Therefore, the natural conditions of the 25 counties are relatively complicated, and the level of social and economic development is relatively backward.

Enrollment number is a major index of ODE development. The average number of learners enrolled in the learning centers per county in the 25 counties from 2012 to 2016 was 183 per year (source from internal statistics of the OUC); while the average number of learners per county in the 132 learning centers in China's top 100 counties was 321 during the same period of time (source from internal statistics of the OUC). It can be seen that the enrollment and development of ODE in the 25 counties were far lower than those in the top 100 counties.

In summary, the 25 counties are relatively faraway and secluded, the level of social and economic development is comparatively lower, and the development momentum and stamina of public transportation, education and other infrastructure and supporting services are insufficient, which to a certain extent restrict people's all-round development in "rural China". In addition, the ODE development in the learning centers of the 25 counties needs to be further improved, and the ability to serve regional learners and economic and social development needs to be strengthened.

\section{Solutions to the poverty problem}

After the poverty alleviation target is identified, the OUC focuses on specific solutions. As the OUC plans to implement poverty alleviation in the form of project management, according to Bai (2006), projects can be conducted from the dimensions of macro, meso and micro. Therefore, the headquarters, heading the project, works out solutions from macro, meso to micro level. At the macro level, policies, rules and regulations are made by the headquarters. At the meso level, the provincial level OUs and the 25 learning centers are responsible for implementing specific policies. And at the micro level, learners with poverty problem are identified.

At the macro level, the headquarters mainly focuses on working out strategies and policies. For providing professional support and guidance, a dedicated poverty alleviation office was set up in April 2017. It has two main roles; one is to rely on open universities in 12 provinces and autonomous regions and learning centers in the 25 counties to form a service system from the headquarters directly to each individual. Within this service system, the headquarters is responsible for top-level strategy design, the provincial open universities coordinate local promotion and the learning centers are the last stop to provide serves to individual learner. This is a vertical working path. The other role is to collaborate with funding organizations, resources companies, computer sellers and other relevant corporate to help. Multi subjects in Chinese society are encouraged to be involved in poverty elimination for these 25 counties. This is a horizontal way of working.

The OUC headquarters has worked out relevant rules and regulations to give instructions to poverty alleviation practice. How to Manage Poverty Alleviation Projects and Managing Poverty Alleviation Funding are just two of them. In these rules and regulations, how to alleviate poverty, working standards, processes, budget, allocation, supervision etc. have been clearly regulated which provide a guarantee mechanism for practice and they are also references for issuing funding where necessary.

Though the OUC implements poverty alleviation in 25 counties at the same pace, different counties have different situations; therefore, the OUC carries out one policy in one county, that is to say, the OUC implements tailor-made policy according to realities. 
At meso level, the provincial OUs work with the local learning centers to provide their specific needs so that the OUC can give targeted support. The OUC first puts forward an assistance menu which lists the resources that can be contributed to local poverty alleviation. The 25 counties, with the assistance of local OUs, work out the proposals of their own actual demands based on the menu. The OUC, according to its budget, reviews and approves the proposals to the most extent after evaluating the real situation of each local county. When the two levels reach an agreement, then support from the headquarters can go to the learning center and individual learners.

At the micro level, according to the characteristics of local residents, specific ways to support them are worked out as follows:

No. 1 To train village leaders and people who can help others make a better living in villages and towns of the 25 counties with no charge. They can register to study with the OUC on diploma or undergraduate level with no entry and no fees.

No. 2 To allow people who are not able to self-finance and have no access to education to study with the OUC on diploma or undergraduate level with no charge.

No. 3 To organize vocational and technical training programs for middle and high school graduates, peasant workers in cities and other peasants in villages and towns based on local industries in the 25 counties.

No. 4 To offer scholarship and stipend for learners so that they can complete their study with no difficulties.

No. 5 To provide ICT capacity building training for K-12 teachers for free.

When policies are made based on research and investigation and targeted potential learners are identified, the OUC invests 58 million RMB to fulfill its commitments. Specific solutions are taken as follows: First, the ICT infrastructure in the 25 learning centers is not updated as fast as in "online China". The OUC helps to set up cloud-based classrooms [1], computer clusters and physical bookstores in the learning centers. These facilities are open to the public locally. These are the premise to conduct education activities. And the aim is to provide ODE in "rural China" as that of in "online China". When building computer classrooms for the learning centers in the counties, the number of computers, printers and laptops are also taken into consideration so that these can be put into use after completion, and relevant digital resources are also selected for the hardware. When bookstores are set up, different sorts of books according to local needs are also ready to assist. The learning centers can also choose the digital learning resources based on their own demands. There are specific differences among different counties.

Second, it also provides qualified degree and non-degree digital learning resources for free. As most local residents rely on their local conditions to make a living, the OUC, taking this feature into consideration, provides loads of digital resources regarding agriculture, forestry, fishery and related areas. The School of Agriculture and Medicine in the headquarters is the main provider for learning resources. So, local learners can learn the theoretical knowledge from the OUC with the updated ICT facilities.

Third, aid registered members and monitor assistance processes strictly. For providing precise support to the local residents, entry qualification of being aided was established and the assistance process has been monitored strictly. The local learning centers of the OUC review the entry qualification of the registered members in order to guarantee that assistance goes to the needed ones. For doing so staff at the learning centers review the application form based on the recruitment database. When training K-12 teachers, only those who are recommended by local education agencies can participate in the training programs. Trainers can accurately and precisely pick up trainee's online learning records to trace their progress and motivate them to complete their assignments and give them feedback without any delay.

Practices of poverty alleviation by ODE 
AAOUJ 16,3

Fourth, organize teaching in an orderly manner. The learners of the OUC are mostly adults who have left schools for many years and receive continuing education with the OUC. Therefore, they focus on practice and pay attention to applying what they have learned into practice. With these features in mind, the OUC explores a specific teaching method for learners in villages and towns, that is, online learning + self-taught and group study + practice. The purpose of such a teaching method is to fully utilize the function of ODE. For online learning, learners can get tutorials, have group discussion and do their assignments or projects together in the cloud-based classrooms. Tutors and class chairs are allocated to each online class. The virtual learning environment creates atmosphere similar to offline classroom, which is helpful for learners to study. For self-taught and group study, either class chair designates a topic or learners select a topic to study. There are "night schools" at villages or towns, and learners can gather together there for group studies. Assignments are presented at online classrooms for peer reviews. For practice, local wellknown teachers and experts are invited to give instructions, lectures or reports to learners and conduct field teaching. They also design and develop teaching and learning materials with local features according to local social and economic development. Practice teaching bases are established in accordance with the existing education resources. All these measures are innovative and effective to deliver ODE to local learners.

Last but not least, the OUC provides fund to the sponsored members. Since the tuition fee in different provinces is different, the OUC makes a precise budget for each county fully considering the differences existed and provides accurate fund for each member whether on undergraduate or diploma level. This guarantees equity.

With social and economic development and the progression of local poverty alleviation, the educational services to the 25 counties need adjusting accordingly. The OUC gives approval to such amendment. More than 30 proposals have been agreed to adjust within current budget and project framework, with the aim of meeting the real needs to the most the extent.

\section{Evaluation of the measures}

After 3 years implementation and development, great progress of the poverty alleviation by the OUC through ODE has been made and listed as below:

\section{ODE in the 25 counties has been improved}

By the end of September 2020, the total amount of 58 million RMB has been invested to the 25 counties 16 cloud-based classrooms and 23 computer rooms have been set up. 25 bookstores have been founded together with 150 thousand books being donated. Around 60 thousand digital micro lectures have been supplied to the learning centers. 46,000 members have been directly benefited. 6,394 village leaders, reserved village leaders, those guiding others to get out of poverty and 981 registered assisted members have been financed to study on either undergraduate or diploma programs. More than 60 vocational training programs including information technology capacity building have been implemented and 12,291 students have received free training. 6,445 students have been awarded $1000 \mathrm{RMB}$, respectively, and 20,701 students each have got 500RMB stipend, as shown in Figure 1.

From the above facts and figures, it can be concluded that the comprehensive capabilities of ODE in the learning centers of the 25 counties have been improved overall, especially in the area of ICT infrastructure, digital learning resources offerings, degree and non-degree education, vocational and technological training. The improvement is demonstrated as below: 


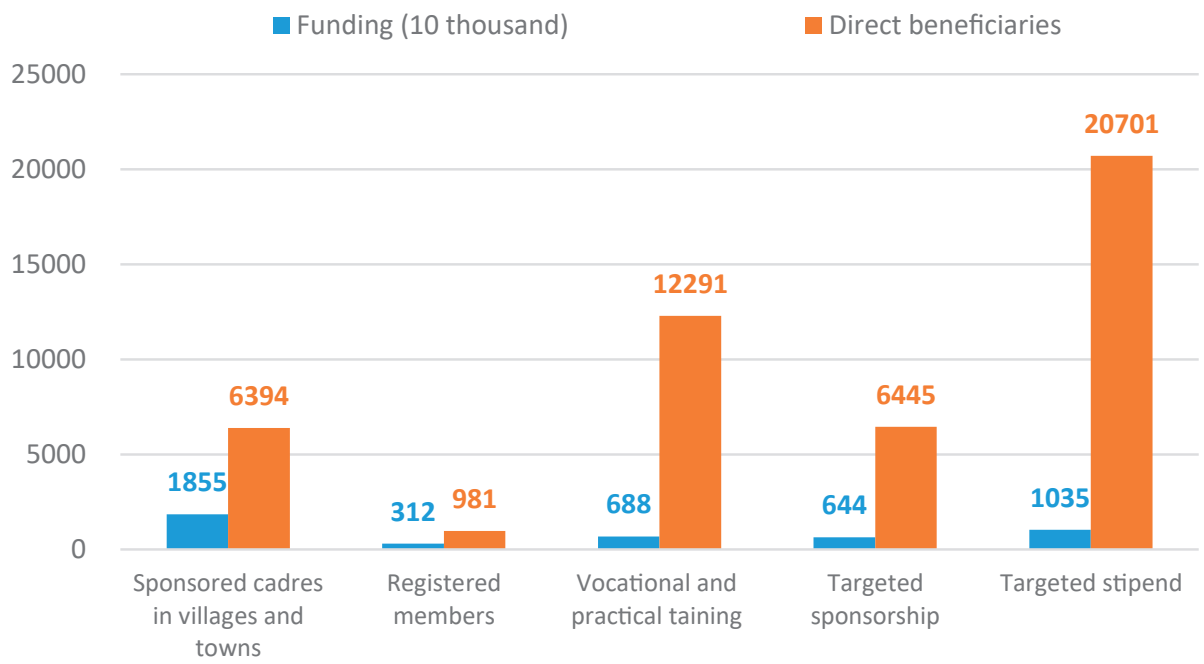

Source: Open University of China (2021), Online Education Cultivates Local talents and Open University Contributes to Education Equity_— Report on poverty Alleviation of National Open University education since the 18th National Congress of the CPC, China Open University Press, Beijing, BJ

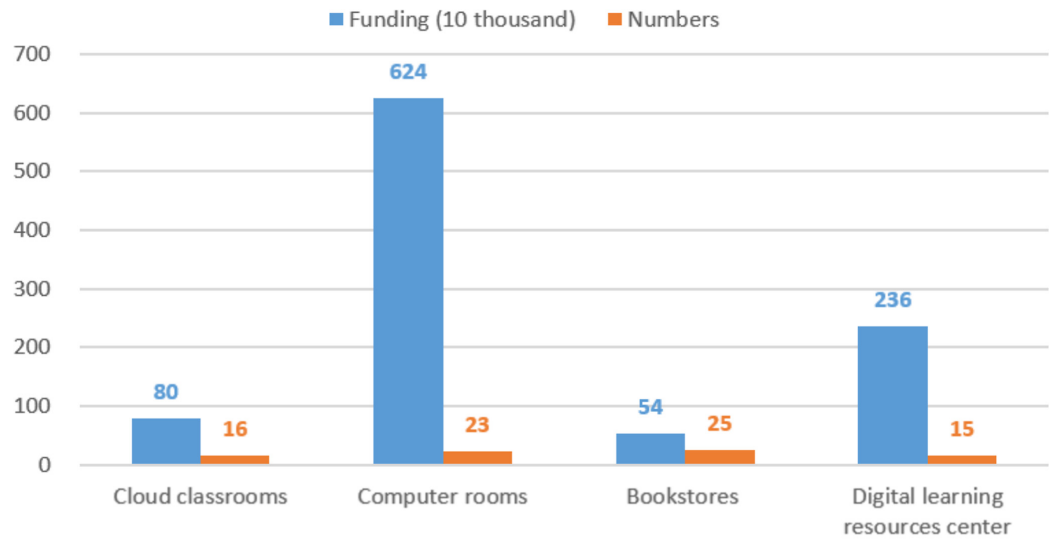

Source: Open University of China (2021), Online Education Cultivates Local talents and Open University Contributes to Education Equity—Report on poverty Alleviation of National Open University education since the 18th National Congress of the CPC, China Open University Press, Beijing, BJ

\section{ODE has been relied on to cultivate talents to get rid of poverty}

Improving talent cultivation: Compared the total enrollment number of the learning centers in the 25 counties from 2012 to 2019 with that of 132 learning centers in China's top 100 counties, the enrollment number in the former is dramatically increased because of the measures taken in Figure 2 since 2017, whereas the enrollment number in the latter remains flat on the whole. It can be easily seen from this comparison that motivated and encouraged by poverty
Practices of poverty alleviation by ODE

293

Figure 1.

Training programs, number of members being trained and financed by the OUC in the 25 counties
Figure 2.

Numbers of cloud classrooms, computer rooms, bookstores and digital learning resources centers that the OUC has financed in the 25 counties 
AAOUJ 16,3

\section{4}

Figure 3.

The total enrollment number of students in 132 learning centers of the OUC in top 132 counties from 2012 to 2019

Figure 4.

The total enrollment number of students in 25 assisted learning centers of the OUC from 2012 to 2019 alleviation policy, a large number of people in villages and towns who wish to improve themselves find a suitable way to build their capacity and further their study through ODE. A great many talents in rural and remote areas have been cultivated and this surely makes contributions to local social and economic development. The comparison is shown in Figures 3 and 4 below:

Many people have successfully got rid of poverty after they complete their training or study with the OUC and they also help others find ways to live a better life. A sample survey to 500 learners has been conducted by the OUC and the results show that about $30 \%$ have taken the post of village leaders guiding other residents find a job; $11 \%$ have successfully run their own business in the field of agriculture, fishery and forestry and grown into farm businessmen; $20 \%$ have found a job in big cities with the knowledge and skills learned from the programs offered by the OUC (the OUC, 2021).

For ODE itself, through these practices, the ICT infrastructure in the 25 counties has been improved which is more convenient for future ODE delivery; teachers including staff have

\section{2 learning centers in China's top 100 counties}

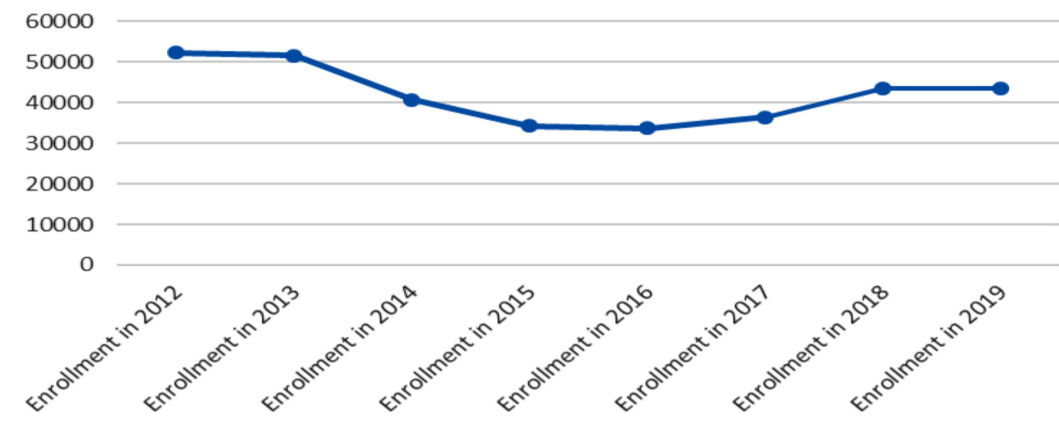

Source: The Open University of Department of Educational Administration of the Open University of China, 2016. Data report on Educational Administration of the Open University of China, China Open University Press, Beijing, BJ

\section{5 assisted learning centers}

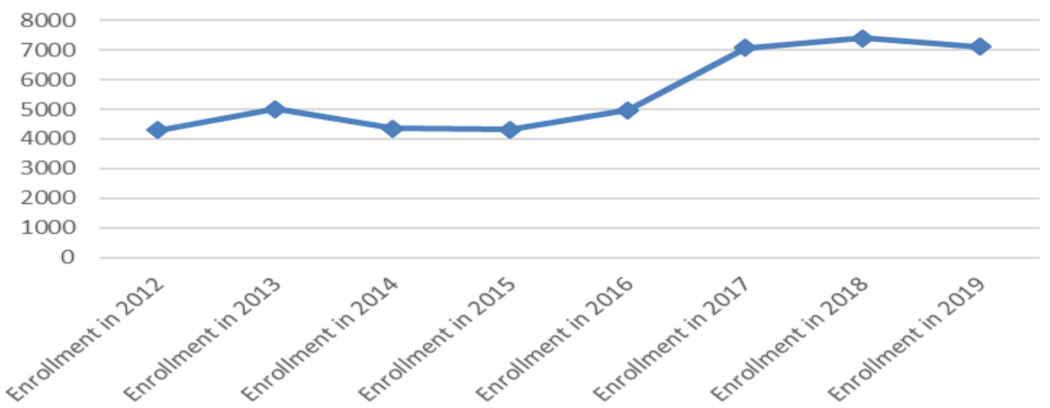

Source: The Open University of Department of Educational Administration of the Open University of China, 2016. Data report on Educational Administration of the Open University of China, China Open University Press, Beijing, BJ 
been trained with ICT skills and their ICT capacities have been improved, for example, teachers in local learning centers can manage to use cloud-based classrooms, and they have mastered the skills of teaching synchronously and asynchronously.

The following are some cases out of the learners:

\section{Case 1:}

Zeng Qikui, 53 years old in 2020, leader of Longyin Village, Wulong Town, Cangxi County, Yunnan province, also a student sponsored by the OUC, owns and runs several ecological industrial parks in the village, such as fish park and chicken park relying on local natural resources. Apart from getting rich for himself, he also helps those poor villagers earn a better living by employing them to work in his ecological industrial parks. Some one used to ask him a question: "You have already got very experienced in operating your ecological parks and raising fish and chicken with mature skills, why do you study and get a degree?" "With fast development of society and economy, knowledge is upgrading very fast. Surely I need to study to keep up with the changes of the era. As a leader in the village, I have to study and arm myself with knowledge, otherwise how can I help those vulnerable? And if peasants are knowing better than me, what is the use to have a leader in a village, such as me?" Zeng expressed it would be never too old to learn, only in this way, can he be able to help the villagers live a better life (Che, 2020).

\section{Case 2:}

Yang Changtai, nearly 50 years old in 2020, with incomplete middle school education experience, went to work in cities a few years ago but returned to his village later on. Then he started to plant seedling without relevant knowledge and skills. No doubt, for the sake of lacking of related experience and knowing very little about market, he lost all his savings and owed 80,000RMB after over two years' hard working. In order to overcome the hardship of life, as a poorest member who needed help, Yang participated in the learning with the OUC, and luckily, he got his diploma on Facility Agriculture Technology with no difficulties. He claimed that: "This diploma program includes both agriculture production, such as seedling planting, raising rice and shrimp together, and marketing and e-commerce training. It is a very practical program." Under the instruction of his tutor, Yang planted small seedlings which were easy to grow, convenient to take care of and cost-effective instead of big seedlings which cost a lot of money. Only half of a year, Yang had earned a net income of more than $100,000 \mathrm{RMB}$. He not only paid the debt, but also became rich himself with extra money. "I am a peasant without much knowledge, however, with the support from the government and the OUC, I have transformed my life with knowledge which empowers me to be a modern peasant." Yang said affectionately (Liang, 2020).

Ding Lina, is a cadre of Tianlong Village, a poor village in Taolin Town, Xishui County, Zunyi city, Gui Zhou province, and a sponsored student of the OUC, plants 50 acres of peppers with her villagers. In 2019, she got 60,000 kilograms of peppers and adopted an orderto-sale model to sign purchase and sales contracts with local companies and lifted 5 households and 12 people out of poverty.

Yuan Ping, cadre of Hong Qi Village in Tongmin Town, Xishui County, Zunyi city, Gui Zhou province, a sponsored student of the OUC, spares no effort to develop mountainous agriculture. Under his instruction, 35 planting households and 24 breeding households have expanded their scales fully taking different features of different agriculture products into consideration. In just one year, villagers' income was increased by more than 800,000 yuan, and their collective economy generated 145,000 yuan in income.

Bai Mingfu, a restaurant boss at Jiulongshan, Donghuang Town, Xishui County, received his cooking training at the learning center of Xishui County. He has earned a lot of money
Practices of poverty alleviation by ODE

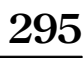


AAOUJ 16,3

after being trained in the Chinese cooking training programs. He applied what he had learned during the training into his restaurant, and the restaurant's turnover increased from around 8,000 yuan per month before the training to around 12,000 yuan, which brought him a tangible increase in profits.

Each living case confirms that it is necessary and feasible to rely on ODE to help the poor and realize "self-rich" and "bringing wealth to others"; a large number of assisted students have gathered into a prairie fire, which will definitely help alleviate poverty and rejuvenate the region.

\section{Conclusion}

2020 marked the ending of absolute poverty in China and education has played an active role in this course. ODE is an important part of driving residents in rural and remote areas out of poverty. In a knowledge-based society, people, wherever they live, cannot make an easy life without knowledge. In China, such a big country with unbalanced social and economic development, education is used to help people to be armed with knowledge though it may take a bit longer time for local residents to adapt to this way (Li, 2021).

In order to eradicate poverty under the national strategy framework, the OUC has been devoted itself in investing ICT infrastructure, providing digital learning resources and facilitating with tailor-made projects to different groups of targets, especially in the past 3 years from 2017 to 2020 . And the sample survey to 500 learners has shown that ODE is an effective way of lifting residents in rural and remote areas out of poverty. These practices reveal three implications, that is, poverty alleviation projects should be designed and developed according to the features of the targeted groups; the services and products of such projects should be delivered to those who really need help and support; and ODE is a necessary part of widening educational access in rural and remote areas.

In the next step, the OUC will effectively connect poverty alleviation and rural revitalization in accordance with the requirements of the Chinese government (Wang, 2021). The first is to spend $3-5$ years as a transition period and continue to invest funds to support rural grassroots cadres and rural residents who have been lifted out of poverty to continue their academic education. The second is to actively seek support from governments in rural and remote areas that have been out of poverty and seek cooperation in the development of continuing education for academic qualifications so as to promote local education development and provide alternative solutions for local governments to cultivate talents.

As the globe is becoming a small village, what the OUC has contributed to poverty alleviation is not only to promote education equity in China but also to provide a case study with rich experience to the open universities in the world. This is hoped to promote a balanced development of education worldwide.

Though the practices are well designed and delivered, there are still shortcomings during the whole process. For example, during the poverty alleviation process, many projects have been implemented, but the effect of each project is not fully evaluated. In this report, only 500 learners are surveyed. And more learners will be surveyed and followed up at the later stage.

\section{Note}

1. Cloud-based classroom refers to a classroom where teachers can conduct teaching activities synchronously or asynchronously and can host online conference to interact with learners based on cloud computing.

\section{References}

Bai, S. (2006), Review of Modern Project Management, [M], Electronic Industry Press, Beijing. 
Bohui Zhao, Z. (2019), Research on Frontier Issues of Poverty Alleviation, China Publishing Group Research Press, Beijing, BJ.

Che, M. (2020), "Learning and growth”, Working Paper, Organization Department of Cangxi County Party committee of CPC and Cangxi branch of Guangyuan radio and TV University, Cangxi.

Chen, En and Chen, L. (2017), Exploration of targeted poverty alleviation in poverty-stricken areas from the perspective of ICT[J], China Educational Technology, No. 03, pp. 58-62.

China Daily (2018), “China's top 100 county economy research results released”, available at: https:// baijiahao.baidu.com/s?id $=1604963096726854087 \& \mathrm{wfr}=$ spider $\&$ for $=$ pc $\quad$ (accessed 26 February 2020).

Department of Educational Administration of the Open University of China (2016), Data Report on Educational Administration of the Open University of China, The Open University Press, Beijing, BJ.

Fei, X. (2013), Local China, Zhonghua Book Company, Beijing, BJ, p. 5.

Institute of Party History and Literature of the CPC Central Committee (2018), Excerpts from Xi Jinping's Treatise on Poverty Alleviation, Central Party Literature Press, Beijing,BJ.

Jing, D. (2021), Beyond Distance Education - Cutting Edge Perspectives on the Future of Global Open Universities, The Open University of China Press, Beijing, BJ, p. 9.

Li, X. (2017), "Value pursuit of education poverty alleviation [J]", Educational Research, Vol. 38 No. 03, pp. 31-37.

Li, Y. (2019), "Analysis of the temporal and spatial development of China's population education under the new situation", Journal of Decision Making Consultation, Vol. 10 No. 2, pp. 6-7.

Li, X. (2021), The End of Poverty, Citic Press, Beijing, BJ.

Liang, D. (2020), "Skill training empowers villagers", available at: http://www.jyb.cn/rmtzgjyb/202002/ t20200204_291359.html.

Open University of China (2021), Online Education Cultivates Local Talents and Open University Contributes to Education Equity_—Report on Poverty Alleviation of National Open University Education Since the 18th National Congress of the CPC, China Open University Press, Beijing, BJ.

Wang, Z. (2021), "Speech at the launch conference of the national action of flourishing 10 thousand villages", Journal of Rural Revitalization in China, Vol. 8 No. 3, pp. 4-5.

$\mathrm{Xi}$, J. (2021), "Speech at the commendation conference on poverty alleviation at the national conference", available at: http://news.hnr.cn/rmrtt/article/1/1364936447794221056.

Yang, J. and Lin, X. (2017), "HEIs in education poverty alleviation: necessity and strategies [J]", Education Induction, No. 09, pp. 83-87.
Practices of poverty alleviation by ODE

. 


\begin{tabular}{|c|c|c|c|c|}
\hline \multirow{2}{*}{$\begin{array}{l}\text { AAOUJ } \\
16,3\end{array}$} & \multicolumn{4}{|c|}{ Appendix } \\
\hline & No & Name & County & Province \\
\hline \multirow{22}{*}{298} & 1 & Ruijin Open University & Ruijin & Jiangxi province \\
\hline & 2 & Shangyou Open University & Shangyou & Jiangxi province \\
\hline & 3 & Nankang Open University & Nankang & Jiangxi province \\
\hline & 4 & Longsheng Open University & Longsheng & Guangxi Zhuang Autonomous Region \\
\hline & 5 & Tiandong Open University & Tiandong & Guangxi Zhuang Autonomous Region \\
\hline & 6 & Tongdao Open University & Tongdao & Hunan province \\
\hline & 7 & Yongshun Open University & Yongshun & Hunan province \\
\hline & 8 & Xishui Open University & Xishui & Guizhou province \\
\hline & 9 & Yinjiang Open University & Yinjiang & Guizhou province \\
\hline & 10 & Huize Open University & Huize & Yunnan province \\
\hline & 11 & Wuding Open University & Wuding & Yunnan province \\
\hline & 12 & Cangxi Open University & Cangxi & Sichuan province \\
\hline & 13 & Rangtang Open University & Rangtang & Sichuan province \\
\hline & 14 & Xiushan Open University & Xiushan & Chongqing city \\
\hline & 15 & Chengkou Open University & Chengkou & Chongqing city \\
\hline & 16 & Lixian Open University & Lixian & Gansu province \\
\hline & 17 & Minxian Open University & Minxian & Gansu province \\
\hline & 18 & Tongxin Open University & Tongxin & Ningxia Hui Autonomous Region \\
\hline & 19 & Xiji Open University & Xiji & Ningxia Hui Autonomous Region \\
\hline & 20 & Shanyang Open University & Shanyang & Shanxi province \\
\hline & 21 & Zhen'an Open University & Zhen'an & Shanxi province \\
\hline & 22 & Yunxian Open University & Yunxian & Hubei province \\
\hline \multirow{3}{*}{$\begin{array}{l}\text { Table A1. } \\
\text { List of the learning } \\
\text { centers in } 25 \text { counties }\end{array}$} & 23 & Yunxi Open University & Yunxi & Hubei province \\
\hline & 24 & Guangshan Open University & Guangshan & Henan province \\
\hline & 25 & Xichuan Open University & Xichuan & Henan province \\
\hline
\end{tabular}

\section{Corresponding author}

Dandan Shao can be contacted at: shaodd@ouchn.edu.cn

For instructions on how to order reprints of this article, please visit our website:

www.emeraldgrouppublishing.com/licensing/reprints.htm

Or contact us for further details: permissions@emeraldinsight.com 